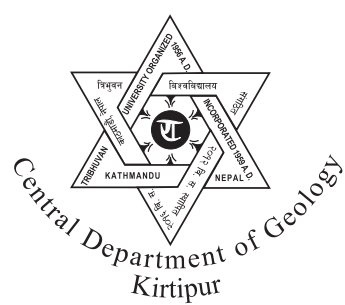

\title{
Feasibility of recharging aquifer through rainwater in Patan, Central Nepal
}

\author{
*Hiterndra Raj Joshi and Suresh Das Shrestha \\ Central Department of Geology, Tribhuvan University, Kirtipur, Kathmandu, Nepal
}

\begin{abstract}
Water is a basic need of lives. Like other aggressively growing town of developing Asian countries, Patan in Lalitpur district of Nepal is also facing water scarcity problem. Since so many people of Patan depend upon groundwater, extraction rate of groundwater in this area is perhaps higher compared to recharge and hence, water table is declining. Urbanization is focused in the central part of Patan on the gravel deposit (Chapagaon Formation) which is the main recharge zone of groundwater, therefore recharge of groundwater could not take place naturally. Encroachment of ponds which were helping to groundwater recharge is also a reason for declining the water table. This study deals with infiltration rates recorded from six different localities of Patan using a single ring percolimeter. The results show that the infiltration rates are higher $\left(10.5 \times 10^{-5} \mathrm{~m} / \mathrm{s}\right)$ at core areas of Patan (Guita aquifer, Khwayebahi aquifer and Emu Dva aquifer) compared to the peripheral areas $\left(1.5 \times 10^{-5} \mathrm{~m} / \mathrm{s}\right) \mathrm{such}$ as Naricha and Nayekyo aquifers. The infiltration rate increases remarkably during dry winter and pre-monsoon periods at the core area of Patan. Infiltration rate decreases during summer and early winter periods. The infiltration rates correlate well with subsurface lithology, i.e., the rates are higher at gravel and lower at clayey sediment (Kalimati Clay). The Patan area is underlain by gravel and sand of the Chapagaon Formation which inturn is underlain by thick clay of the Kalimati Formation. The zone above the clay is the shallow aquifer zone and the zone below the clays is the deep aquifer zone. There are 39 ponds and more than 218 shallow dug wells which may be utilised for recharging shallow aquifers through rainwaters. Most of the ponds and shallow dug wells which lie on the Chapagaon Formation are suitable for recharge purpose due to good infiltration rate in the formation. Historical stone spouts can also be utilized as a recharge medium. Adequate rainfall, good infiltration rate, and distribution of many recharge media allow aquifer recharge in Patan through rainwater.
\end{abstract}

\section{INTRODUCTION}

Groundwater has become a major natural resource contibuting the water supply system in Patan, Lalitpur district of Nepal (Fig. 1). People of Patan have been using groundwater since ages through dug wells and stone spouts. Usually groundwater gets recharged during rainfall period. Due to urbanization, surface infiltration has been vastly reduced while consumption of groundwater is ever rising (UDLE 1993a). Hence water table has gone down over the years. Since

*Corresponding author:

E-mail address: hitendra_joshi@hotmail.com many people rely on groundwater as there is no drinking water supply and pipe line system in the central areas, the traditional water supply system through dug wells and stone spouts needs to be preserved. Finding suitable and applicable recharge method of groundwater through rainwatermay help to solve present water problem in Patan.

JICA (1990) worked on sediments and aquifer system of Patan and reported that shallow aquifer is potential in reserving water as the leakage from the shallow aquifer into deep one is very low because of underlying clay sediment. UDLE (1992) surveyed stone spouts of Patan and reported their architectures. 


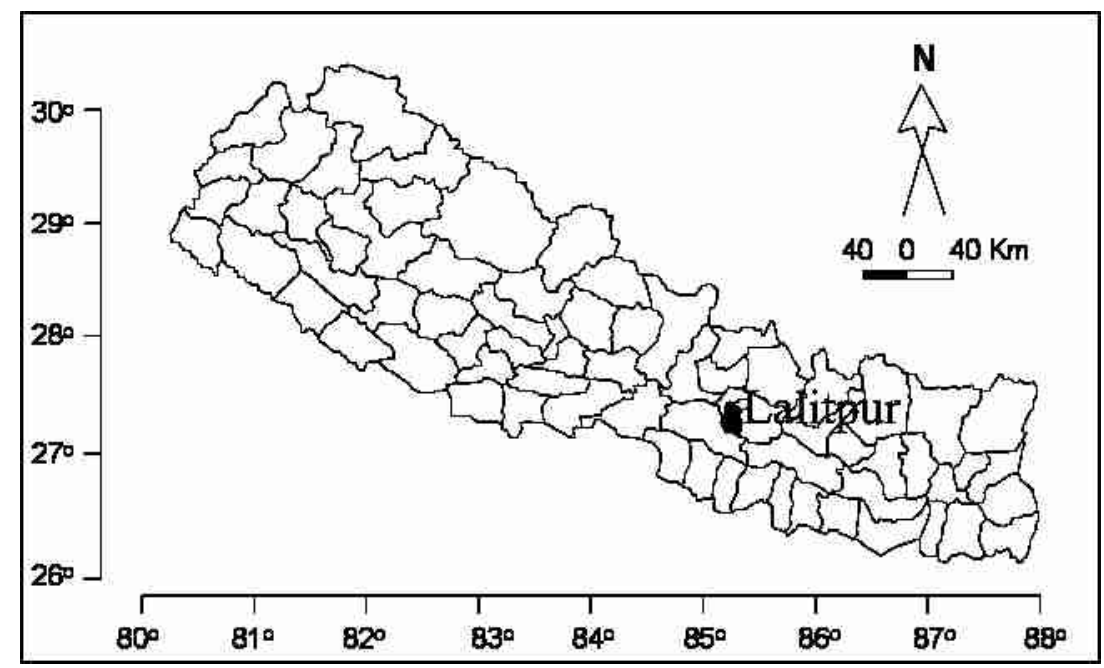

Fig. 1 Location map of study area

UDLE (1993a) distinguished various aquifer zones in Patan and measured infiltration rates.

The main objectives of the present study were to identify recharge zone with sufficient percolation rate for recharge purpose and to suggest suitable media to recharge groundwater.

\section{MATERIAL AND METHOD}

The information required in generating the picture of water table below groundwater level and distribution of aquifer, stone spouts and shallow dug well was obtained from the reports of UDLE (1992, 1993a and 1993b). The geological information about distribution of sediments and geological formations were obtained from the map of DMG (1998) and the report of JICA (1990). For aquiring the infiltration rate, a single ring percolimeter (Sanders 1998) was used at six different areas. The test was made by fitting a percolimeter in the ground. The ground was was wetted before reading data to reduce error which could occur becasue of surface tension of soil.

\section{HYDROGEOLOGICAL SET UP}

Patan is drained by the Bagmati River with its tributaries forming centripetal drainage pattern (UDLE 1993a). Rainfall distribution in Patan from the data recorded in the Khumaltar Station by Department of Hydrology and Meteorology for the period between 1990 and 2004 has been shown in Fig. 2. Patan experiences maximum average annual rainfall of $1114 \mathrm{~mm}$ (Fig. 2), and warm temperate climate. About $80 \%$ of the rainfall occurs during monsoon (DHM 2005).

Fluvio-lacustrine deposits of the Kathmandu Valley can be divided into eight stratigraphic units among which Patan area constitutes the Chapagaon Formation and the Kalimati Formation (Yoshida and Igarashi 1984). In central and southeastern parts, the Chapagao Formation is exposed overlying the Kalimati Clay (DMG 1998). Proportion of the Kalimati Clay is high around the Bagmati River and the proportion of the Chapagaon Formation increases in the central portion of Patan (Fig. 3). Two types of aquifer, i.e., deep aquifer and shallow aquifer were identified in the valley sediment of Patan, separated by the Kalimati Clay (JICA 1990).

\section{Deep aquifer}

Recharge to the deep aquifer occurs exclusively through water squeezed from the confining strata or leakage from the unconfined shallow aquifer through the confining strata (JICA 1990). Leakage from the shallow aquifer into the deep aquifer can be expected 
very low as the Kalimati Clay (Fig. 3) acts as a vey strong aquiclude.

\section{Aquitard}

The Kalimati Clay consists of thick clay layers with occasional silt and sand bed withing lignite layers which act as an aquitard bordering the shallow and the deep aquifers. The Kalimati Clay is exposed at the periphery of Patan (Fig. 3).

\section{Shallow aquifer}

The Chapagaon Formation (Fig. 3) consists of silty sandy gravel. The Recent Flood Plain Deposits of the Bagmati RIver are not in direct hydraulic contact with the shallow aquifer. Groundwater flow direction of the shallow aquifer is directed towards NE (Fig. 5). Distortion to this pattern is found in the north of Durbar Square area, where an approximately E-W extending anomaly provokes a groundwater mound and indicates direction of the former Bagmati River course (UDLE 1993a). UDLE (1993a) identified six aquifer zones in Patan; Guita aquifer, Emu Dva aquifer, Naricha aquifer, Nayekhyo aquifer, Khwayebahi aquifer and Jawalakhel aquifer (Fig. 4).

\section{GROUNDWATER STATUS OF PATAN IN 2006 MARCH}

\section{Aquifers}

The results of percolation tests are given in Table 1. Depending on infiltration rate, aquifers were categorised into three types as: Aquifer A with infiltration rate less than $2 \times 10^{-5} \mathrm{~m} / \mathrm{s}$, aquifer $B$ with infiltration rate between $2 \times 10^{-5} \mathrm{~m} / \mathrm{s}$ and $4 \times 10^{-5}$ $\mathrm{m} / \mathrm{s}$, and aquifer $C$ with infiltration rate greater than $4 \times 10^{-5} \mathrm{~m} / \mathrm{s}$.

Groundwater table fluctuates significantly with the variation of rainfall. In rainy season, it rises up quickly and in dry season it dries up considerably. Slopes of Patan diminish from SW to NE. Water level of dug wells also follows this pattern. Thick layers of the Kalimati Clay at the outskirts of Patan protect the flow path from seeping into the Bagmati River, while creating potential aquifers in the north. This explains why in the northern zone, most stone spouts yields more water than those existing in the other regions of Patan. Groundwater level contour below ground level concentrated at Mangal Bazar (Fig. 5)

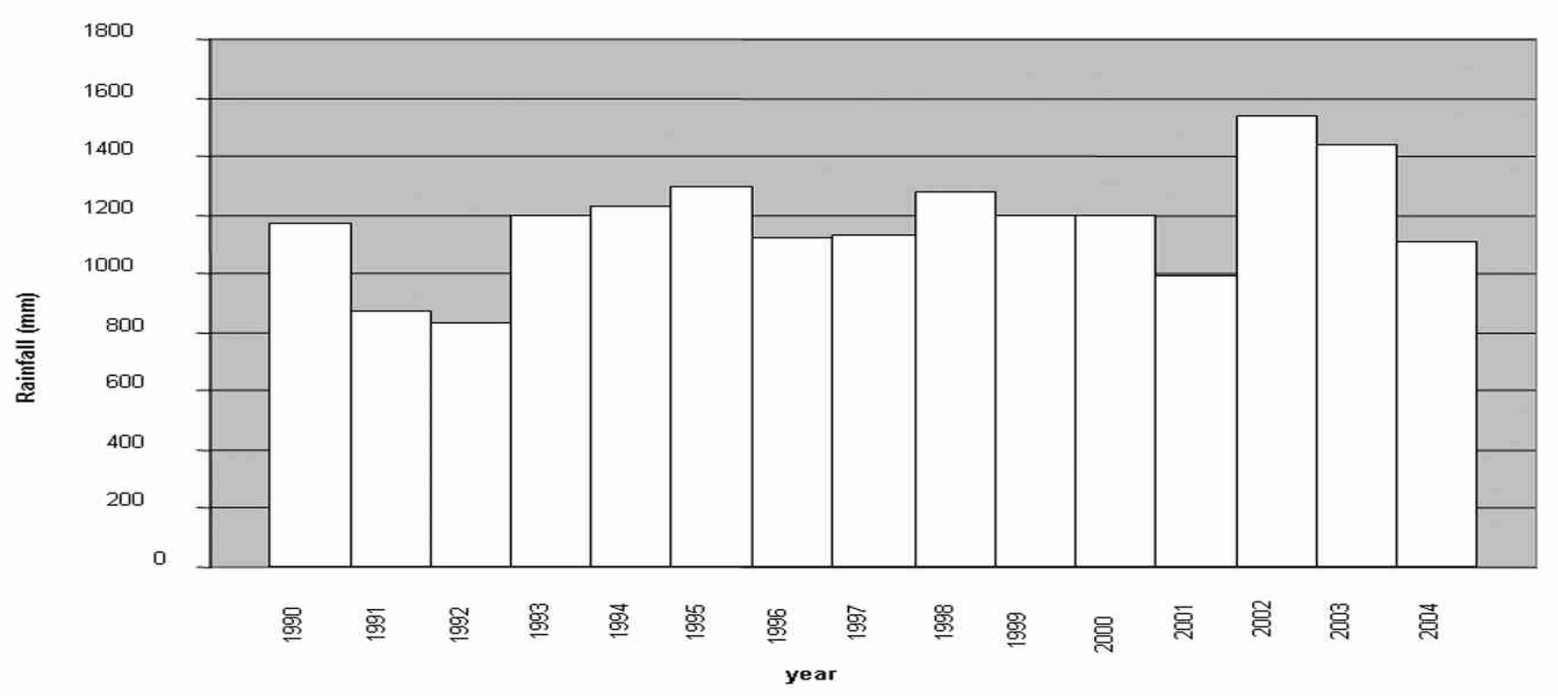

Fig. 2 Yearly rainfall distribution in Khumaltar Station near Patan between 1990 and 2004 (Data taken from Department of Hydrology and Meteorology 


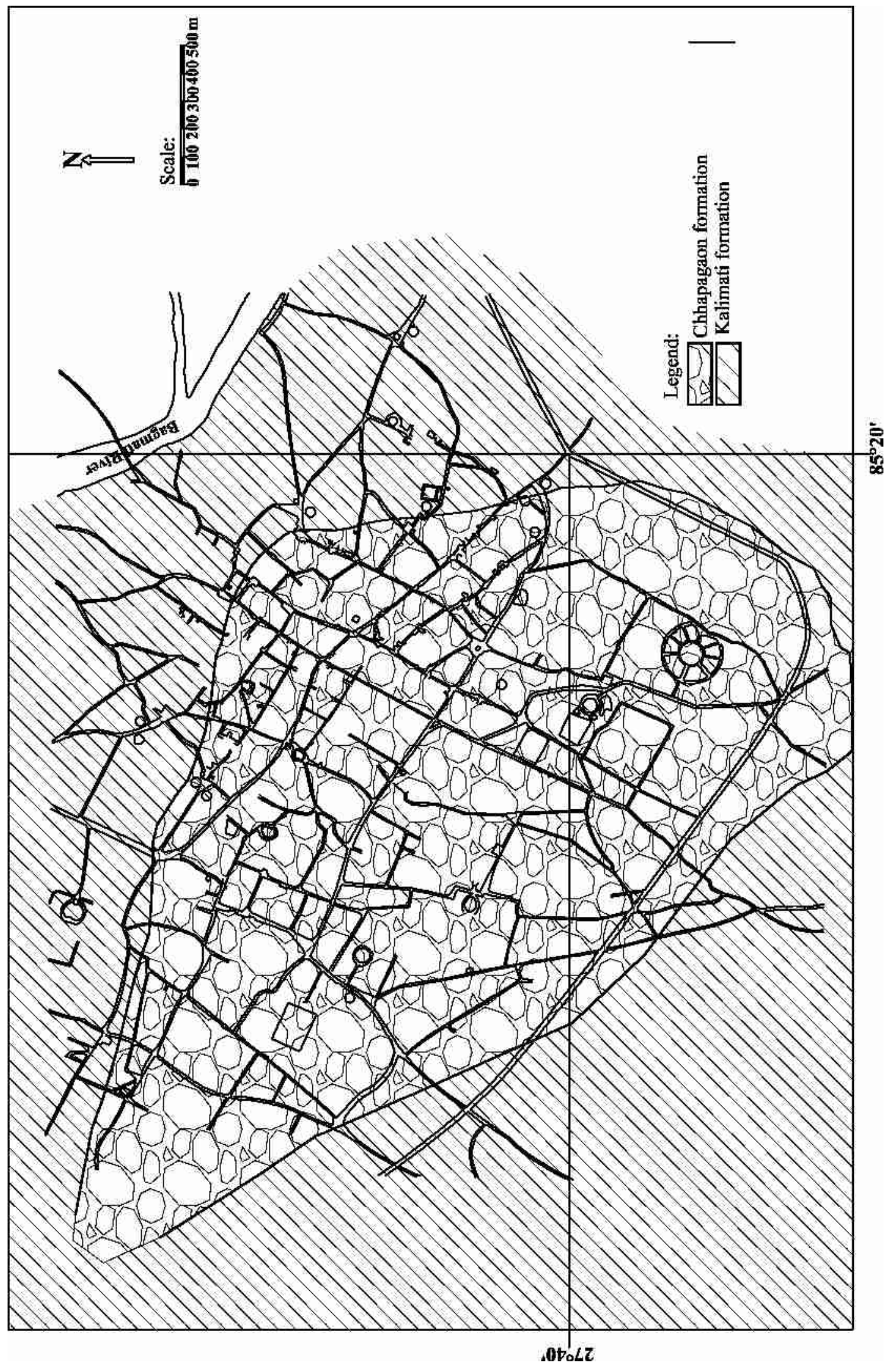

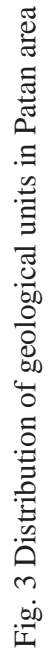




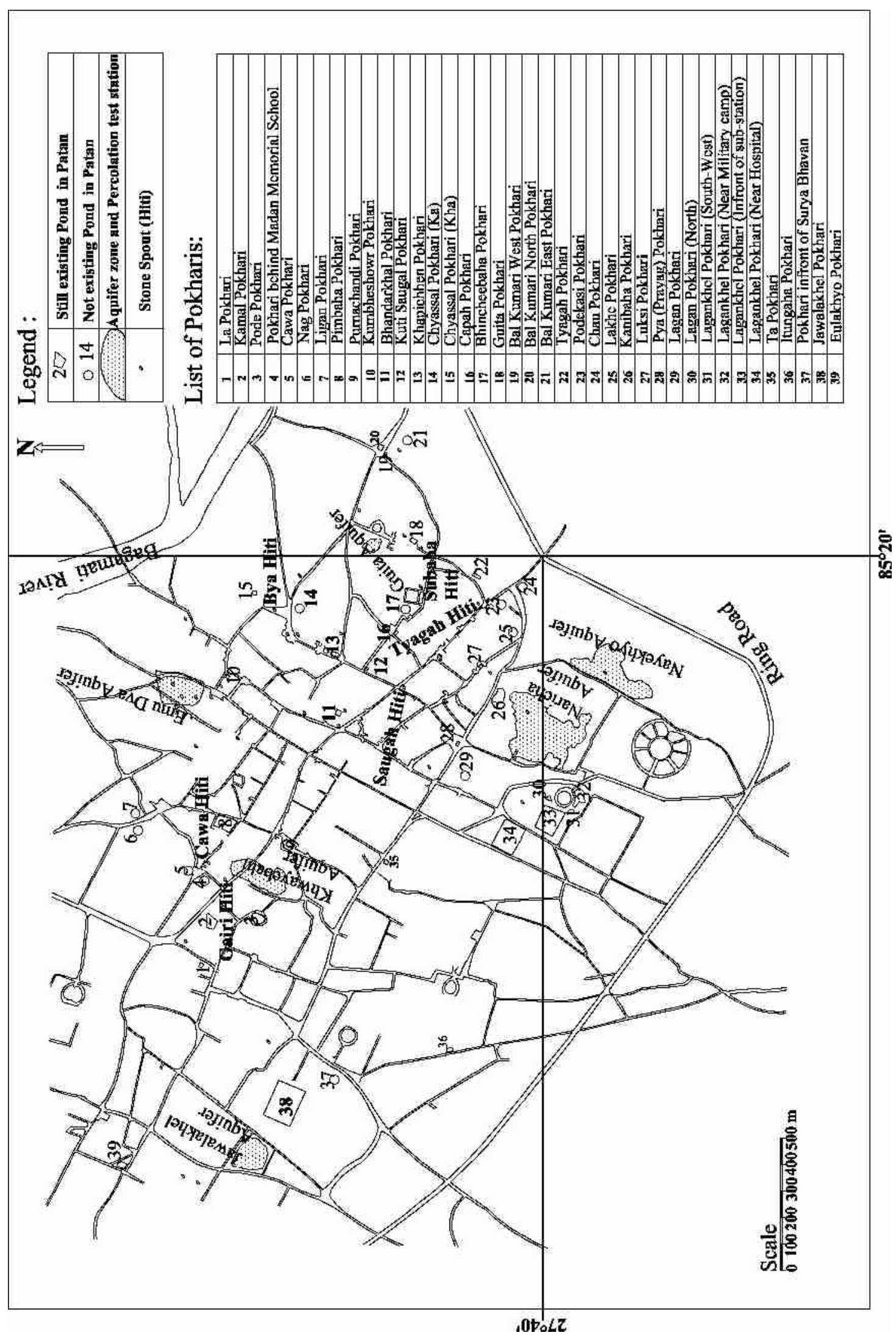


Table 1: Infiltration rate of aquifer zones according to infiltration test conducted on 1st March 2006

\begin{tabular}{lc}
\hline Aquifer & Infiltration rate $(\mathrm{m} / \mathrm{s})$ \\
\hline Naricha & $1.17 \times 10^{-5}$ \\
Nayekhyo & $1.76 \times 10^{-5}$ \\
Guita & $4.43 \times 10^{-5}$ \\
Emu Dva & $2.62 \times 10^{-5}$ \\
Khwayebahi & $3.30 \times 10^{-5}$ \\
Jawalakhel & $120 \times 10^{-5}$ \\
\hline
\end{tabular}

and indicates high amount of water extraction in the surrounding. Groundwater contours below ground level increases from SW to NE indicating groundwater flow direction towards NE (Fig. 5).

\section{Status of ponds, stone spouts and dug wells}

Altogether there were 39 ponds in Patan (Fig. 4). Among the 39 ponds, Rajkulo (drainage) connects 18 , rainwater feeds 5 local springs nearby aquifers, and stone spouts feeds 11 ponds. Supply source of 5 ponds is unknown. Out of 39 ponds, 14 ponds do not exist at present (UDLE 1993b). There exist 34 stone spouts in Patan (UDLE 1992). Rapid urbanization that seals recharge areas and overextraction of groundwater are causes which diminish water table and help in drying up stone spouts. There are more than 200 dug wells in Patan excluding people owned dug wells. Increase in numbers of dug wells and decrease in rechargable surface areas are triggering groundwater problem in Patan.

\section{RAINWATER HARVESTING METHODS ON ARTIFICIAL RECHARGE OF AQUIFER}

Aquifer can get recharged in two ways naturally and artificially. In natural recharge, rainwater and surface water get percolated into shallow or deep aquifer by itself through uncovered soil surface or fissures on the rock mass. In artificial recharge, water is percolated using different methods to recharge shallow aquifer. The techniques of artificial recharge can be categorised after Central Groundwater Board
Ministry of Water Resources, New Delhi (CGBMWR 2002) as follows:

\section{Surface spreading method}

This method is suitable where large area of basin is available and is can be applied in three ways.

1. Flooding method: This method is suitable for flat topography where water can be spread as a thin sheet.

2. Basin and percolation tank method: In this method, water is impounded in series of basins or percolation tank. The size of basin may depend upon the topography of area.

3 Ditch and furrows method: This method is suitable for irregular topography where ditch and furrows provide maximum water contact area for recharge.

\section{Subsurface methods}

Subsurface methods apply recharging media lying below ground level. Three ways by which subsrface recharge can be applied are

1. Recharge wells: Dug wells can be used as recharge wells for shallow aquifer. These wells could be of dry or wet. Dry well should be most appropriate for recharging purpose

2. Pits and shafts: In areas where impervious layer is encountered at shallow depth, the pits and shafts are suitable structure for artificial recharge, and

3. Soak away or percolation pits: A soak away is a bored hole up to $0.3 \mathrm{~m}$ diameter drilled in the ground to the depth of 3 to $10 \mathrm{~m}$.

\section{FEASIBILITY OF RAINWATER RECHARGE IN AQUIFERS OF PATAN}

The huge amount of water received from rainfall during monsoon goes in wastage as surface flow. If it could be collected in ponds and wells, it will minimize groundwater level diminishing problem in Patan by balancing water table. The method and principles are based on Sadgir (2006). The following calculation may be considered in estimating the volume of rainfall that could be recharged.

Average annual height of rainfall $(\mathrm{H})$ in Patan is 


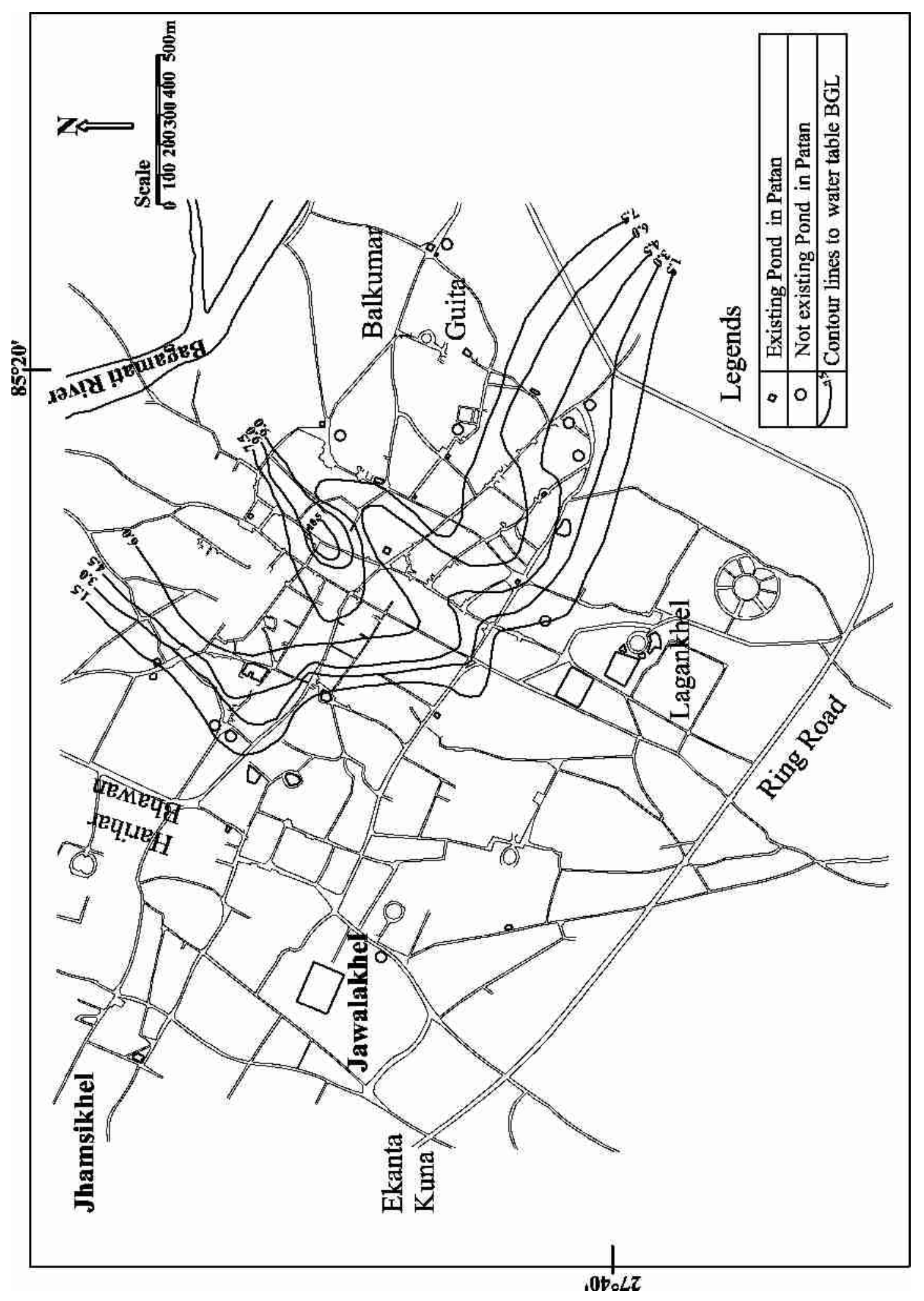

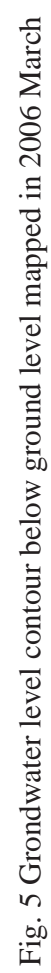


Table 2: Runoff coefficient for various catchments surfaces after UN habitat

\begin{tabular}{lll}
\hline Types of catchment & Coefficient \\
\hline Roof catchments & & \\
Tiles & 0.8 & 0.9 \\
Corrugated metal sheets & 0.7 & 0.9 \\
Ground surface covering & & \\
Concrete & 0.6 & 0.8 \\
Brick pavement & 0.5 & 0.6 \\
Untreated ground catchments & & \\
Soil on slope < 10\% & 0.0 & 0.3 \\
Rocky natural area & 0.2 & 0.5 \\
Green area & 0.05 & 0.10 \\
\hline
\end{tabular}

$1.11 \mathrm{~m}$ (Fig. 3). Total surface area of Patan (A) approaches 6569269.2 square meters. Average amount/volume $(\mathrm{V})$ of rainfall that falls on Patan area can be estimated as A x H =7,291,888.81 cubic meters.

Rainwater harvesting is influenced mainly by two factors, i.e. rainfall and catchment area characteristics. Rainfall is the most unpredictable variable in the calculation. Hence to determine potential rainwater supply for a given catchments reliable rainfall data are required. The number of annual rainy days also influences the need and design for rainwater harvesting. If the dry period is long, big storage tanks would be required to store rainwater. hence, in such regions, it is more feasible to use rainwater to recharge groundwater rather than storing into tanks. The total amount of water that is received in the form of rainfall over an area is rainwater catchments of the area and the amount that can be effectively harvested is water harvesting potential. Type of catchment and runoff coefficient of the catchment influence in quantity of rainwater which can be effectively harvested (Table 2). Runoff coefficient for catchments is the ratio of the volume of the water that runs off the surface to the value of rainfall that falls on the surface.

Amout of rainwater which gets recharged in the given surface area may require the total area of covered and uncovered zone, infiltration rate of those percolation zones and hurly rainfall data of the zones. In case if all required data can be accumulated and calculated, one can calculate exact amount of water
Table 3: Information of ponds in Patan

\begin{tabular}{|c|c|c|c|c|}
\hline & \multicolumn{2}{|c|}{ Chapagaon Formation } & \multicolumn{2}{|c|}{ Kalimati Clay } \\
\hline Total no. of ponds & 28 & & 11 & \\
\hline Existing ponds & 21 & $75 \%$ & 4 & $36.4 \%$ \\
\hline Non existing ponds & 7 & $25 \%$ & 7 & $63.6 \%$ \\
\hline
\end{tabular}

which gets percolated and amount of water which gets overland flow.

\section{RECHARGE OF SHALLOW AQUIFERS IN PATAN}

Recharge area of shallow aquifers is restricted to the central portion of Patan because of geomorphologic positions of the aquifers. Annual surface runoff can be expected very high and about $80 \%$ of the average precipitation falls during monsoon season. Except rainwater, shallow aquifers get recharged through historical drainages (Rajkulos), ponds and stone spouts. Historical Rajkulos greatly contribute to keep groundwater level within reach of approximately 70 dug wells and 18 ponds (Table 3 ) in the rural area on the route of Patan around Chapagaon, Thecho and Sunakothi (UDLE, 1993a). Ponds of prime importance to the aquifer recharge within Patan are aligned in SSE NNW (including Lagankhel ponds cluster, Pulchowk pond cluster and several other clusters).

\section{Sources of water}

In Patan excessive amount of groundwater extraction takes place regularly but very few people seems to be conscious about recharging aquifers. Due to insufficient recharge of groundwater, water level fluctuates $1.5 \mathrm{~m}$ during dry season (UDLE 1993a). The major source of recharge can be the rainwater as Patan obtains sufficient amount of annual rainfall $(1114 \mathrm{~mm})$. Sufficiency to feed shallow aquifers depends not only upon meteorological factor but also on topographical, geological and anthropogenic factors.

Surface geology of Patan containing gravel depositis at the core of the city surrounded by clay makes the city very suitable for recharging aquifers 
and the gravel surrounded by clay near the Bagmati River ceases direct leakage of the groundwater into the river. Therefore, the whole Patan area can be thought of as a bowl like aquifer.

\section{Recharging media}

\section{Ponds}

Several ponds in Patan function as a basin percolation tanks which are supplied with water by Rajkulo, stone spouts or rainfall. Most of the ponds are situated in gravel deposits of the Chapagaon Formation (Fig. 3 and 4) except the ponds 6, 7, 14, $17,18,19,20,21,22$, and 24, which are situated on the Kalimati Clay among which ponds 6, 7, 14, 17 and 21 do not exist at present but their traces have been still preserved. Remaining 28 ponds are situated on the Chapagaon Formation. Most of the ponds which have ried or do not exist lie either on the Kalimati Clay or near the Kalimati Clay. Ponds located on the Chapagaon Formation may be taken as very effective medium of recharging shallow aquifers.

Water of ponds is recharged with certain rate. The main objective of ponds in Patan is to recharge aquifer. But many ponds are dirty and contaminated. Before using such ponds as a recharge medium, these should be cleaned, fenced and maintained regularly.

\section{Stone spouts}

Surplus water from some stone spouts (Hitis) pours into nearby pond to aid aquifer recharge. For example, Ligan pond receives water from nearby Gairi spouts and Cawa spouts. Similarly Khapinchen pond receives water from nearby Saugah spout, Chyassal pond 'Kha' receives from Bya spout, Balkumari pond receives from Guitar and Subaha spouts, and Tyagah pond receives water from Tyagah spout. Most of the stone spouts are scattered and located at sediments of the Chapagaon Formation in Patan. Therefore stone spouts can be reliable medium by which aquifer recharge may be effectively made.

\section{Shallow dug wells}

There are more than 218 shallow dug well in Patan. Wells are drying due to declining water level. These wells can be improved and utilized as a recharging medium because wells are themselves connected to shallow aquifers and are very effective in recharging aquifers. Infiltration rate does not affect recharge through wells so wells can be an appropriate medium for those areas where infiltration rate is comparatively low. But the dug wells distributed in Patan are in poor condition and there are chances of contamination due to household activities. Therefore, these wells are required to be improved and cleaned before using as recharge wells.

\section{CONCLUSIONS}

Groundwater flow trend of the shallow aquifer in general is towards NE direction. At the southern part of Patan, around Lagankhel, the infiltration rate is low, at the northern and central parts the rate is medium and aquifer at the eastern part has high infiltration rate.

The Chapagaon Formation containing coarse sand and gravel lies at the core area of Patan and favors groundwater recharge. The infiltration rate increases remarkably during dry winter and pre-monsoon periods at the core area of Patan. Infiltration rate decreases during summer and early winter periods.

Ponds which lie on the Chapagaon Formation are suitable for recharge purpose due to its good infiltration rate. Most shallow dug wells in Patan are situated in the Chapagaon Formation, and can also be utilized as recharge wells. Historical stone spouts can also be utilized as a recharge medium. In overall, good rainfall amount, good infiltration rate, and distribution of many recharge media allow aquifer recharge in Patan through rainwater. If it is possible to apply effectively, then it will be the example of rainwater harvesting into a very large natural tank of Patan.

\section{ACKNOWLEDGEMENTS}

Authors are thankfull to the Central Department of Geology, Tribhuvan University for providing laboratory facility. Authors thank Urban Development through Local Effort (UDLE) and P. R. Joshi for providing materials and literatures. Authors also thank B. Lamichhane, M. B. Khadka, D. Maharjan and A. Pradhan for providing assistance during sampling and field works. 


\section{REFERENCES}

CGBMWR, 2000. Guide on artificial recharge to groundwater. A report of Central Groundwater Board Ministry of Water Resources, New Delhi, p. 59.

DHM, 1998. Hydrological records of Nepal, stream flow summary, Department of hydrology and meteorology (DHM), Ministry of science and technology, Kathmandu, Nepal.

DMG, 1998. Engineering and Environmental geological map of Kathmandu, Department of Mines and Geology, Lainchaur, Kathmandu, Nepal.

JICA, 1990. Groundwater management project in Kathmandu Valley. Final Report, Japan International Cooperation Agency, Kathmandu, Nepal, p. 34.

Sadgir, P.A., Patil, G.K. and Takalkar, V.G., 2006. Sustainable watershed development by refilled continuous contour trenching technology. pp. 18 .
Sanders, L.L., 1998. A field manual of filed hydrogeology. p. 367.

UDLE, 1993a. Rehabilitation potential of the traditional water supply system, Lalitpur, Nepal. Unpublished report of Urban Development through Local Effort, Kathmandu, Nepal, p. 43.

UDLE, 1993b. Feasibility study of Rajkulo: rehabilitation of Patn's traditional water supply network. Unpublished report of Urban Development through Local Effort, Kathmandu, Nepal, p. 93.

UDLE, 1992. Historical hitis and pokharis: traditional solution to water scarcity in Patan. Unpublished report of Urban Development through Local Effort, Kathmandu, Nepal, p. 21.Yoshida, M. and Igarashi, Y., 1984. Neogene to Quaternary lacustrine sedimetns in Kathmandu Valley, Nepal. Journal of Nepal Geological Society, Special Issue, v. 4, pp. 73100. 